\title{
Introduction: Advances in IoT research and applications
}

\author{
Pan Wang • Ricardo Valerdi • Shangming Zhou • Ling Li
}

Published online: 11 March 2015

(C) Springer Science+Business Media New York 2015

The future of the Internet will consist of heterogeneously connected devices that will further extend the borders of the world with physical entities and virtual components. The Internet of Things (IoT) is a term that has been introduced in recent years to describe objects equipped with digital functionality that are able to communicate via the Internet (Li 2013; Reaidy et al. 2015), and it is considered as a part of the Internet of the future. Kevin Ashton firstly proposed the concept of IoT in 1999, and he referred the IoT as uniquely identifiable interoperable connected objects with radio-frequency identification (RFID) technology. IoT can comprise billions of intelligent communicating 'things', allowing people and things to be connected anytime, anyplace, with anything and anyone, ideally using any path/network and any service (Perera et al. 2015); as such, IoT will empower the connected things with new capabilities (Li et al. 2015a). In recent years, IoT has drawn significant research attention, evidenced by the number of survey papers written on the IoT subject published ( $\mathrm{Li}$ et al. 2015a; Perera et al. 2015; Whitmore et al. 2015; Xu et al. 2014).

IoT is becoming an emerging Internet-based industrial information architecture that is employed to facilitate informa-

\footnotetext{
P. Wang $(\bowtie)$

Wuhan University of Technology, Wuhan, Hubei, China

e-mail: wangpan@whut.edu.cn

R. Valerdi

University of Arizona, Tucson, AZ, USA

S. Zhou

Swansea University, Swansea, UK

L. $\operatorname{Li}(\square)$

Old Dominion University, Norfolk, VA, USA

e-mail: LLi@odu.edu
}

tion flows among supply chain networks across the globe. The significance of IoT to supply chain management lies in streamlining supply chain operations, providing real time information, and tracking business processes at various stages. Many new opportunities in applying IoT to supply chain management are available today or can be foreseen in near future (Bi and Cochran 2014; Li 2012; Xu 2013).

In this evolving process, IoT and its related supporting platforms have to be rapidly formed and designed in order to meet industrial demands. There are a plethora of issues needed to be addressed. These issues have been the central themes at a series of related conferences organized by IEEE, IFIP, ACM, and other societies including IFIP's Confenis, IEEE SMC International Conference on Enterprise Systems, and other conferences.

The purpose of the Special Issue is to report on the state-ofthe-art of, and emerging trends in research and practice of IoT. It provides a premier forum for researchers to present research results in all areas ranging from architecture, design, implementation, to the evaluation of IoT as it is permeating and integrating into industries and business.

This special issue of Information Systems Frontiers presents expanded versions of six papers from the abovementioned conferences held recently, authored by scholars from the US, Sweden, and China. To prepare for this issue, all authors were asked to respond to at least two rounds of peer review. Each paper emphasizes the importance of IoT from a unique perspective.

The problem of food safety is a critical issue in recent years. To address this issue, IoT can be used to track the processes in the stages such as production, storage, and transportation. In the paper entitled "The design of an electronic pedigree system for food safety", an electronic pedigree system for food 
safety is introduced, which uses electronic pedigrees to manage the safety of food (Han et al. 2015). The system implements an extension of the pedigree standard of EPCglobal, and also offers a trustworthily tracking service to monitor and supervise the production and supply of food.

Continuing on the topic of food safety, the revolution of IoT is reshaping modern food supply chains for a changing world. In the paper entitled "Value-centric design of the internet-of-things solution for food supply chain: value creation, sensor portfolio and information fusion", the authors propose a value-centric business-technology joint design framework as well as the development and implementation of the corresponding sensor portfolios (Pang et al. 2015). A three-tier information fusion architecture is proposed as well as application examples. The feasibilities of the proposed design framework and technical solution are proven by an implemented system.

Floods and water resource management are one of the major challenges in many countries and areas. Snowmelt floods usually break out in arid or semi-arid regions which cause tremendous economic losses. The paper entitled "An integrated information system for snowmelt flood early-warning based on internet of things" presents an integrated systems approach to early warning systems for snowmelt flood using technologies such as geoinformatics, geographical information systems, global positioning systems, IoT, cloud computing, and enterprise systems (Fang et al. 2015). The system implemented in this study is valuable to the collection and sharing of multi-source information in snowmelt flood earlywarning; furthermore, the project has significant social and economic impact.

Continuing on the topic of environmental issues, there is a global trend of diminishing of natural resources, such as wildlife, waters, and others, which have suffered dramatic diminishing due to habitat loss and over use, and increasingly caused by global warming. To make the planet more sustainable, abundant data has to be collected and analyzed from ecosystems for scientific decision-making to restore and preserve natural resources. In the paper entitled "An integrated systems approach to plateau ecosystem management-a scientific application in Qinghai and Tibet plateau", an integrated systems approach has been proposed for the data acquisition and analysis for ecosystems (Liu et al. 2015). In the study, an IoT-based system has been applied to investigate the effects of the signal transducer and activator of transcription 3 (STAT3) on the adaptation mechanism to high altitude hypoxia.

IoT is a current trend that leads the next generation Internetbased information architecture that involves integration of social networks and inter-object communications (Wang et al. 2014). In the paper entitled "The role of social media in supporting knowledge integration: a social capital analysis", the authors investigate the role of social media in supporting knowledge integration from a social capital perspective, in an IoT environment (Cao et al. 2015).

Complex product design requires a long and intricate process (Gao et al. 2013; Wang et al. 2007; Wang and Xu 2008; Wilamowski et al. 1999; Xing et al. 2013; Xu et al. 2007; Yu et al. 2014); and mostly, it is of the multidisciplinary nature (Wilamowski and Kaynak 2000). The design can become even more challenging if the product to be designed is completely new as numerous technical challenges and uncertainties are involved. In the paper entitled "Risk assessment model based on multi-agent systems for complex product design", the risk assessment for complex product design is discussed, with the consideration of the complex product design in the IoT based manufacturing environment ( $\mathrm{Li}$ et al. 2015b).

As the organizers of the above-mentioned IEEE and IFIP conferences, we are delighted to share this sampling of the conferences with the readership of Information Systems Frontiers. We hope that this special issue will serve our Information Systems Frontiers readers as an avenue to gain a current perspective on IoT. We would specially like to thank the Editors-in-Chief, Professor R. Ramesh and Professor H.R. Rao, for their encouragement, support, and guidance throughout this endeavor. We are also deeply grateful to the anonymous reviewers for their careful reading of our manuscripts and their many insightful comments and suggestions. Without their time, effort, and support, this issue would never have come to be.

\section{References}

Bi, Z., \& Cochran, D. (2014). Big data analytics with applications. Journal of Management Analytics, 1(4), 249-265.

Cao, X., Guo, X., Liu, H., Gu, J. (2015). The role of social media in supporting knowledge integration: a social capital analysis. Information Systems Frontiers, 17(2). doi: 10.1007/s10796-0139473-2.

Fang, S., Xu, L., et al. (2015). An integrated information system for snowmelt flood early-warning based on internet of things. Information Systems Frontiers, 17(2). doi: 10.1007/s10796-0139466-1

Gao, X., Xu, L., Wang, X., Li, Y., Yang, M., \& Liu, Y. (2013). Workflow process modeling and resource allocation based on polychromatic sets theory. Enterprise Information Systems, 7(2), 198-226.

Han, W., Gu, Y., et al. (2015). The design of an electronic pedigree system for food safety. Information Systems Frontiers, 17(2). doi: 10.1007/ s10796-012-9372-y.

Li, L. (2012). Effects of enterprise technology on supply chain collaboration: analysis of China-linked supply chain. Enterprise Information Systems, 6(1), 55-77.

Li, L. (2013). Technology designed to combat fakes in the global supply chain. Business Horizons, 56(2), 167-177.

Li, S., Xu, L., \& Zhao, S. (2015a). The internet of things: a survey. Information Systems Frontiers, 17(2). doi:10.1007/s10796-014-9492-7.

Li, N., Li, X., Shen, Y., Bi, Z., Sun, M. (2015b). Risk assessment model based on multi-agent systems for complex product 
design. Information Systems Frontiers, 17(2). doi: 10.1007/s10796013-9452-7.

Liu, F., Bi, Z., Xu, E., et al. (2015). An integrated systems approach to plateau ecosystem management - a scientific application in Qinghai and Tibet plateau. Information Systems Frontiers, 17(2). doi: 10. 1007/s10796-012-9406-5.

Pang, Z., Chen, Q., Han, W., Zheng, L. (2015). Value-centric design of the internet-of-things solution for food supply chain: value creation, sensor portfolio and information fusion. Information Systems Frontiers, 17(2). doi: 10.1007/s10796-012-9374-9.

Perera, C., Liu, C., \& Jayawardena, S. (2015). The emerging internet of things marketplace from an industrial perspective: a survey. IEEE Transactions on Emerging Topics in Computing. doi:10.1109/ TETC.2015.2390034.

Reaidy, P., Gunasekaran, A., \& Spalanzani, A. (2015). Bottom-up approach based on internet of things for order fulfillment in a collaborative warehousing environment. International Journal of Production Economics, 159, 29-40.

Wang, C., \& Xu, L. (2008). Parameter mapping and data transformation for engineering application integration. Information Systems Frontiers, 10(5), 589-600.

Wang, C., Xu, L., \& Peng, W. (2007). Conceptual design of remote monitoring and fault diagnosis systems. Information Systems, 32(7), 996-1004.

Wang, L., Lei, C., Xu, Y., Yang, Y., Shan, S., \& Xu, X. (2014). An information dissemination model of product quality and safety based on scale-free networks. Information Technology and Management, 15(3), 211-221.

Whitmore, A., Agarwal, A., \& Xu, L. (2015). The internet of things-a survey of topics and trends. Information Systems Frontiers, 17(2). doi:10.1007/s10796-014-9489-2.

Wilamowski, B., \& Kaynak, O. (2000). Oil well diagnosis by sensing terminal characteristics of the induction motor. IEEE Transactions on Industrial Electronics, 47(5), 1100-1107.
Wilamowski, B., Jaeger, R., \& Kaynak, O. (1999). Neuro-fuzzy architecture for CMOS implementation. IEEE Transactions on Industrial Electronics, 46(6), 1132-1136.

Xing, Y., Li, L., Bi, Z., Wilamowska-Korsak, M., \& Zhang, L. (2013). Operations research (OR) in service industries: a comprehensive review. Systems Research and Behavioral Science, 30(3), 300-353.

$\mathrm{Xu}, \mathrm{L}$. (2013). Introduction: systems science in industrial sectors. Systems Research and Behavioral Science, 30(3), 211-213.

Xu, L., Li, Z., Li, S., \& Tang, F. (2007). A decision support system for product design in concurrent engineering. Decision Support Systems, 42(4), 2029-2042.

$\mathrm{Xu}, \mathrm{L} ., \mathrm{He}, \mathrm{W} .$, \& Li, S. (2014). Internet of things in industries: a survey. IEEE Transactions on Industrial Informatics, 10(4), 2233-2243.

Yu, J., Xu, L., Bi, Z., \& Wang, C. (2014). Extended interference matrices for exploded view of assembly planning. IEEE Transactions on Automation Science and Engineering, 11(1), 279-286.

Pan Wang received the B.S. degree in industrial automation from Wuhan University of Technology (WHUT), Wuhan, China, in 1994 and the M.S. and Ph.D. degrees in systems engineering from Huazhong University of Science and Technology, Wuhan, in 1998 and 2003, respectively. He is with the School of Automation and the Institute of Systems Science and Engineering (ISSE), WHUT, where he is a Professor and the Vice Director of ISSE. His research interests are in the fields of intelligent control and optimization, decision analysis, and biomedical intelligent information systems. He has published 3 monographs, over 50 refereed journal papers in journals such as IEEE Transactions on Industrial Electronics, IEEE Systems Journal, and others. Dr. Wang is a member of the Technical Committee on Enterprise Information Systems of IEEE Systems, Man, and Cybernetics Society, and Working Group 8.9 of the International Federation for Information Processing (IFIP). He is a Fellow of the China Creative Studies Institute. 